\title{
TITLE: A PILOT STUDY: VIDEOPHONES IN A PEDIATRIC DAYCARE SETTING
}

Kimmo Murto FRCPC ${ }^{*}$, Khalid Chowdary FCPS*, Ibrahim Abushahwan MD*, Greg Bryson FRCPC ${ }^{\mathfrak{f}}$, Nick Barrowman $\mathrm{PhD}^{\S}$, Bonnie Molinski RN, Uwe Schwarz MD*, and William Splinter FRCPC*.

"Department of Anesthesiology and ${ }^{\S}$ Chalmer's Research Group, Children' sHospital of Eastern Ontario 401 Smyth Rd. Ottawa Ontario K1H8L1, ${ }^{\mathfrak{E}}$ Department of Anesthesiology, The Ottawa Hospital, 1053 Carling Ave. Ottawa Ontario K1Y4E9

INTRODUCTION: Information and communication technology (ICT) will play an inevitable role in health care delivery of the future ${ }^{1}$. We hypothesized that communication between staff and parents by means of a videophone in the postoperative day care setting would be received favorably.

METHODS: After ethics committee approval two Tandberg $1000^{\circ}$ videophones, one placed in our recovery room and the other placed in a private parent waiting room, were used to communicate postoperatively between attending staff (surgeon and/or recovery room nurse) and parents. Twentyfive children undergoing short duration minor day care surgery were randomly enrolled. After surgery the attending staff involved with the patient' care spoke with the parents over the videophone. Those involved were asked to anonymously respond after the encounter to a seven-item questionnaire evaluating the technical aspects of the equipment, surroundings, confidentiality and overall satisfaction. Responses were rated from 1 (agree strongly) to 5 (disagree strongly). Written comments were allowed. All data are described as proportions or medians. Groups were compared with MannWhitney U test.

RESULTS: A 98\% response rate was achieved. Other than audio clarity, the public had a more favorable impression of the technology compared to staff (Table 1). This reached statistical significance in the areas of facility comfort, confidentiality and satisfaction. Concerns about the impersonal nature of the technology were raised by both groups but to a greater extent with staff. Eighty-seven percent of parents and $83 \%$ of staff were neutral to strongly in favor of promoting this technology.

Table 1

\begin{tabular}{|c|c|c|c|}
\hline Question & $\begin{array}{c}\text { Parent } \\
(\mathrm{N}=25)\end{array}$ & $\begin{array}{c}\text { Staff } \\
(\mathrm{N}=30)\end{array}$ & P value \\
\hline Audio clarity & 2 & 2 & 0.104 \\
\hline Video clarity & 1 & 2 & 0.081 \\
\hline Facility comfort & 1 & 3 & 0.000 \\
\hline Confidentiality & 1 & 2 & 0.007 \\
\hline Ease of use & 1 & 2 & 0.395 \\
\hline Recommend use & 1 & 2 & 0.100 \\
\hline Satisfaction & 1 & 2 & 0.026 \\
\hline
\end{tabular}

DISCUSSION: Our pilot study conveys an acceptance of videophone technology in the hospital setting by staff and more so by parents. There are concerns about the impersonal aspect of it and audiovisual quality. Advantages may include improved confidentiality and efficient allocation of health care staff. Further evaluation is required in the pediatric perioperative care setting.

\section{REFERENCE:}

${ }^{1}$ Social Science \& Medicine 52:1889-1901 